\title{
A Bayesian Spatial Propensity Score Matching Evaluation of the Regional Impact of Micro-finance
}

\author{
ROLANDO GONZALES* \\ Bayesian Institute for Research \& Development \\ PATRICIA ARANDA \\ Bayesian Institute for Research \& Development
}

JOEL MENDIZABAL

\begin{abstract}
Bayesian Spatial-Propensity Score Matching is proposed to measure the regional impact of microfinance on poverty reduction and women's empowerment. The impact of microfinance in Bolivia was tested with this method, using census and household survey data. The results suggest that microfinance was useful for poverty reduction and women's empowerment at municipality level in Bolivia
\end{abstract}

Keywords: Bayesian methods, microfinance, spatial statistics, matching estimators.

JEL Classifications: C11, C31, G21

\section{Introduction}

Microfinance is the provision of small-scale financial services to low-income clients who lack access to traditional banking services (Karlan and Goldberg, 2007). The impact of microfinance is a subject of controversy: proponents of microfinance-as the Nobel Laureate Muhammad Yunus or World Bank's President Jim Yong Kim—state that microfinance reduces poverty through higher employment and higher incomes, which in turn improves health and education.

\footnotetext{
* Director - senior researcher, Bayesian Institute for Research \& Development. Miraflores Park Building, Office A1, La Paz, Bolivia. PO Box: 177. Telephone: +591 67308747. Email: rgonzales@bayesgroup.org.

Acknowledgements: This research work was carried out with financial and scientific support from the Partnership for Economic Policy (PEP) (www.pep-net.org) with funding from the Department for International Development (DFID) of the United Kingdom (or UK Aid), and the Government of Canada through the International Development Research Center (IDRC). The comments and suggestions of Milford Bateman, Jorge Dávalos, Luca Tiberti, Abdelkrim Araar, two external reviewers from PEP and two referees from the Review of Economic Analysis were useful to improve the scope of the paper.
}

(C) 2017 Rolando Gonzales, Paricia Aranda and Joel Mendizabal. . Licensed under the Creative Commons Attribution - Noncommercial 3.0 Licence. (http://creativecommons.org/ licenses/by-nc/3.0/). Available at http://rofea.org. 
Detractors of the microfinance model disbelieve in the poverty-reduction role of microfinance and further suggest that microfinance is damaging the possibility of development due to crowding out effects (see, e.g., Bateman, 2010). The evaluation of the impact of microfinance tends to be qualitative and based on anecdotal evidence — see Weiss and Montgomery (2005) for a review — or focused at individual or household level, as in Banerjee et al. (2015). To our knowledge, an impact evaluation of the effects of microfinance at regional level was never carried out with a Bayesian approach before.

In this study, Bayesian Spatial-Propensity Score Matching (BS-PSM) was used to measure the regional impact of microfinance. The regional effects of microfinance can arise when the impact of micro-credit spreads out beyond target clients and towards other economic agents within the same geographical unit and/or neighbouring units, due to the economic interaction between the recipients of microfinance and the non-participant population. The findings obtained with the BS-PSM model suggest that microfinance was useful for poverty reduction and women's empowerment at the municipal level in Bolivia, with the possible cost of increasing informality.

Section 2 offers a brief literature review about the regional impacts of microfinance. Section 3 describes the BS-PSM method. Section 4 presents an application for the Bolivian case. Section 5 discusses the results and concludes. Appendix I at the end of the paper shows a falsification test performed to evaluate the quality of the BS-PSM algorithm by testing the effects of microfinance on deafness. Appendix II performs a sensitivity analysis of the results to the matching technique and the exclusion of spatial effects. The MATLAB codes used in the study are available upon request.

\section{Regional Impact of Micro-Finance}

The analysis about the impact of microfinance tends to be exclusively focused on the direct impact on microfinance clients (Chowdhury et al., 2004). In contrast, the regional impacts of microfinance affect non-client beneficiaries and do not operate primarily at the individual or household level (Zohir and Matin, 2004). These wider regional effects are commonly measured through spatial models of the type described in inter alia Anselin (1988), Arbia (2010), Anselin and Florax (2011) or Griffith and Paelinck (2011), as at the regional level the probability of having access to microfinance is influenced by the proximity to other regions with financing facilities, and the dynamics of one local economy influences neighbouring local economies, through trade linkages and market relationships—such as demand linkages and interregional mobility of production factors - with a level of influence spatially bounded by the distance between regions (Capello, 2009).

The regional impacts of microfinance on poverty can arise due to income spillovers from microfinance beneficiaries to other members of a community where microfinance is offered 
GONZALES, ARANDA, MENDIZABAL Bayesian Evaluation of Micro-finance Impact

(Glennerster and Takavarasha, 2013); negative externalities may also arise if microfinance institutions give priority to weak and generally short-lived informal enterprises over riskier but longer-term enterprises (Bateman, 2013), which can cause a displacement effect if the informal microenterprises and self-employment ventures crowd out the operations of formal and sustainable small-medium enterprises with prospects of technological upgrading, which are widely seen as the source of formal employment and growth in developing and transition countries_-see Bateman and Chang (2009), Bateman (2010) or Bateman (2013).

In terms of women's empowerment, Glennerster and Takavarasha (2013) provide a nice example of the potential regional effects of gender-oriented microfinance: positive effects within a community can arise if women who take up microfinance will start businesses and employ their neighbours to help them, thereby sharing some of their increased income with their neighbours. Thus, even women who do not borrow may benefit from being in a community where microfinance is offered. Negative externalities arise if women with existing businesses are harmed by the arrival of microfinance because they will face more competition from new borrowers who start businesses that cater to the local community and offer similar products, thus affecting those in the community who do not take up microfinance.

Empirical studies about the wider impacts of microfinance are inter alia Mosley (2003), Mosley and Rock (2004), Khalily (2004), Wright and Copestake (2004), Chowdhury and Bhuiya (2004), Johnson (2004), Velasco and Marconi (2004) or McIntosh (2008). In terms of positive effects, these studies found that microfinance has the potential to stabilize income at the community level (Mosley, 2003), generate derived demand and other economic effects through the labour market (Mosley and Rock, 2004) and assist microenterprises in maintaining an increased level of output and investment during recessions (Velasco and Marconi, 2004). In terms of negative effects, Velasco and Marconi (2004) found that the entry of consumer credit houses into microcredit could destabilize loan discipline and the entire bottom end of the financial system.

Studies that analysed the impact of microfinance in Bolivia are inter alia MkNelly and Dunford (1999), Navajas et al. (2000), Mosley (2001), Brett (2006), Velasco and Marconi (2004) and Gonzales (2010). MkNelly and Dunford (1999) compared a baseline of nutritional data with a control group of communities who would be offered the same nutritional program two years later. No evidence of improvements in household food security or nutritional status of client's children relative to the control group was found by MkNelly and Dunford (1999). Navajas et al. (2000) compared poverty in income terms of a sample of the borrowers of five microfinance organizations with the poverty of all households in La Paz, a major city of Bolivia. Navajas et al. (2000) found that microfinance organizations tended to serve not the poorest but rather those near the poverty line. Using data of borrowers of microfinance in Bolivia and a control sample with a before-after methodology, Mosley (2001) found that the growth of incomes and assets of borrowers always exceeds that of control group, but no evidence of this 
effect was found for the extreme poor. More recently, in his suggestive ethnographic article “We Sacrifice and Eat Less: The Structural Complexities of Microfinance Participation”, Brett (2006) found that, having borrowed money from a microfinance organization to start a small business, many women in El Alto, Bolivia are unable to generate sufficient income to repay their loans and so must draw upon household resources. Finally, Gonzales (2010) analysed the regional impact of credit for economic development and found that on average municipalities with access to financial services have better human development indicators.

Even if Velasco and Marconi (2004) or Gonzales (2010) analysed the regional impacts of microfinance access in Bolivia before, due to the recent availability of the 2012 Census of Bolivia, there is new data to perform a more accurate assessment about the regional impact of financial access in this country. Also, previous studies did not perform a rigorous impact evaluation, and as BS-PSM is a spatial quasi-experimental design, it is a methodological improvement over past studies.

\section{Bayesian Spatial-Propensity Score Matching}

This section describes the quasi-experimental matching model used to measure the regional effects of microfinance. Let $\mathbf{t}$ be a $n \times 1$ vector of binary values that reflect the absence/presence of microfinance in a municipality $i=1, \ldots, n$. The spatial spillover effects of microfinance can be estimated with a Spatial Error Model (SEM) with spatial influence captured through an error term $\varepsilon$,

$$
\left\{\begin{array}{l}
\mathbf{t}=\mathbf{X} \beta+\varepsilon, \\
\varepsilon=\rho \mathbf{W} \varepsilon+v, \quad v \sim \mathcal{N}\left(0, \sigma_{v}^{2} \mathbf{I}_{n}\right)
\end{array}\right.
$$

where $\rho$ is a spatial correlation coefficient, $\mathbf{W}$ is a $n \times n$ row-stochastic proximity matrix between municipalities -i.e. a real square matrix, with each row summing to 1 - and $\mathbf{X}$ is a $n \times$ $p$ matrix of $p$ control covariates for these $n$ municipalities,

$$
\mathbf{X}=\left(\begin{array}{ccc}
x_{11} & \cdots & x_{1 p} \\
\vdots & \ddots & \vdots \\
x_{n 1} & \cdots & x_{n p}
\end{array}\right)
$$

which can be used to capture spatially auto-correlated shocks in the error term (Elhorst, 2014). The Bayesian latent variable treatment for modelling this type of spatial limited dependent variables treats the binary 0,1 observations in $\mathbf{t}$ as indicators of a latent, unobserved (net) utility of a spatial agent in an $i$-municipality. Formally, based on the difference in utilities $u_{1 i}-u_{0 i}$, $i=1, \ldots, n$, associated with observed 0,1 choice indicators, the probit model assumes that the difference $t_{i}^{*}=u_{1 i}-u_{0 i}$ follows a Gauss-Laplace distribution, and, as $t_{i}^{*}$ is unobservable, 
GONZALES, ARANDA, MENDIZABAL Bayesian Evaluation of Micro-finance Impact

then $t_{i}=1$ if $t_{i}^{*} \geq 0$ and $t=0$ si $t_{i}^{*}<0$. This implies $\mathbb{P}\left(t_{i}=1\right)=\mathbb{P}\left(u_{1 i} \geq u_{0 i}\right)=\mathbb{P}\left(t_{i}^{*} \geq\right.$ $0) .{ }^{1}$ Thus, a general likelihood for the SEM model is,

$$
\mathcal{L}\left(\mathbf{t}, \mathbf{W} \mid \beta, \rho, \sigma_{v}^{2}\right)=\frac{1}{2 \pi \sigma_{v}^{2 n / 2}}\left|\mathbf{I}_{n}-\rho \mathbf{W}\right| \exp \left\{-\frac{1}{2 \sigma_{v}^{2}} \varepsilon^{\prime} \varepsilon\right\}
$$

for $\varepsilon=\left(\mathbf{I}_{n}-\rho \mathbf{W}\right)(\mathbf{t}-\mathbf{X} \beta)$. With a diffuse prior for $\beta, \rho, \sigma_{v}^{2}$, a joint posterior for this parameters is,

$$
\mathbb{P}\left(\beta, \rho, \sigma_{v}^{2} \mid \mathbf{t}, \mathbf{W}\right) \propto\left|\mathbf{I}_{n}-\rho \mathbf{W}\right| \sigma_{v}^{-(n+1)} \exp \left\{-\frac{1}{2 \sigma_{v}^{2}} \varepsilon^{\prime} \varepsilon\right\}
$$

with a kernel,

$$
\mathbb{P}\left(\sigma_{v}^{2} \mid \beta, \rho\right) \propto \sigma_{v}^{-(n+1)} \exp \left\{-\frac{1}{2 \sigma_{v}^{2}} \varepsilon^{\prime} \varepsilon\right\}
$$

for the conditional posterior of $\sigma_{v}^{2}$ and,

$$
\begin{aligned}
& \mathbb{P}\left(\beta \mid \rho, \sigma_{v}^{2}\right) \sim \mathcal{N}\left(\tilde{\beta}, \sigma_{v}^{2}\left(\mathbf{X}^{\prime} \mathbf{B}^{\prime} \mathbf{B} \mathbf{X}\right)^{-1}\right) \\
& \tilde{\beta}=\left(\mathbf{X}^{\prime} \mathbf{B}^{\prime} \mathbf{B} \mathbf{X}\right)^{-1}\left(\mathbf{X}^{\prime} \mathbf{B}^{\prime} \mathbf{B} \mathbf{t}\right) \\
& \mathbf{B}=\left(\mathbf{I}_{n}-\rho \mathbf{W}\right)
\end{aligned}
$$

for the conditional multivariate normal distribution of $\beta$. The conditional distribution of $\rho$ given $\beta$ and $\sigma_{v}^{2}$ is,

$$
\mathbb{P}\left(\rho \mid \beta, \sigma_{v}^{2}\right) \propto\left|\mathbf{I}_{n}-\rho \mathbf{W}\right| \sigma_{v}^{-(n+1)} \exp \left\{-\frac{1}{2 \sigma_{v}^{2}} \varepsilon^{\prime} \varepsilon\right\}
$$

LeSage (2000) proposed a Markov Chain Monte Carlo (MCMC) sampler to draw samples from this last distribution; see also LeSage and Pace (2009). Based on the probabilities estimated

\footnotetext{
${ }^{1}$ See Smith and LeSage (2004) for a detailed discussion on the Bayesian latent variable treatment of probit models. Smith and LeSage (2004) motivate the basic probit model in terms of an explicit choicetheoretic context involving individual behavioural units, which exhibit spatial interaction effects due to the varying spatial location of the decision makers. That is, individuals located at similar points in space may tend to exhibit similar choice behaviour with a spatial grouping of individuals by region based on the assumption that individuals within each region are homogeneous and thus the spatial dependencies and heteroscedastic effects occur at the regional level. Albert and Chib (1993) provide a less formal economic interpretation and view the latent variable simply as unobserved values associated with observed choice events.
} 
with the SEM, matching estimators can be used to compare the outcome of a treated region (in this case a municipality with access to microfinance) with the outcome of comparison group members (municipalities without access to microfinance). Let $\hat{p}:=\mathbb{P}\left(t_{i}=1\right)=f(\hat{\rho} \mathbf{W} \varepsilon, \mathbf{X} \widehat{\beta})$ be the estimated probabilities of a spatial probit model. A traditional pairwise nearest-neighbor matching between treated and untreated municipalities is,

$$
C_{n n}(\hat{p})=\min _{j}\left\|\hat{p}_{i}-\hat{p}_{j}\right\|, j \in n_{0}
$$

where $n_{0}$ denotes the set of untreated municipalities (i.e. those without microfinancial access). In this type of matching the score of a $i$-treated municipality is compared with the scores of all the $j$-untreated municipalities in order to find a single untreated municipality with a similar score. NN matching faces the risk of bad matches, if the closest neighbour is too far away (Caliendo and Kopeinig, 2008). This problem can be avoided by imposing a tolerance level on the maximum propensity score distance, i.e. a calliper: let $\delta$ be a proximity measure among municipalities, captured through the distance matrix $\mathbf{W}$, if $\delta$ is considered when performing the matching,

$$
C_{s c}(\hat{p}, \boldsymbol{W})=\min _{j}\left\|\hat{p}_{i}-\delta_{j} \hat{p}_{j}\right\|, \quad j \in n_{0}
$$

the propensity score $\hat{p}_{i}$ of a $i$-treated municipality with access to microfinance is compared only with the propensity scores of nearby municipalities without access to microfinance: $\delta_{j}$ is a binary vector with entries equal to one for the $j$-untreated municipalities geographically close to the treated municipality $i$, and zero in other cases. This is a type of spatial calliper matching (SCM), where the tolerance (the calliper) is given by the geographical proximity among regions. Thus, SCM is a type of spatial nearest-neighbour matching that compares the outcome of a $i$-treated municipality with that of the single closest untreated municipality (the one minimizing the distance $\left\|\hat{p}_{i}-\delta_{j} \hat{p}_{j}\right\|, j \in n_{0}$ ). The spatial (regional) average treatment effect (SATE) that could be estimated with this method will be:

$$
\begin{aligned}
\text { SATE }:=\vartheta_{u}= & \mathcal{M}(\mathbf{t}, \mathbf{W}, \mathbf{X}, \mathbf{y}, \boldsymbol{\Theta}) \\
= & \mathbb{E}_{\mathbf{W}, \boldsymbol{\Theta}}\left\{\left(y_{i} \mid t_{i}=1, X_{1 i}=x_{1}, \ldots, X_{p i}=x_{p}\right)-\left(y_{i} \mid t_{i}=0, X_{1 i}=\right.\right. \\
& \left.\left.x_{1}, \ldots, X_{p i}=x_{p}\right)\right\}
\end{aligned}
$$

for a regional outcome variable $\mathbf{y}$, a matching function $\mathcal{M}(\cdot)$ and $\left\{\beta, \rho, \sigma_{v}^{2}\right\} \in \boldsymbol{\Theta}$ a stacked vector of parameters of the spatial discrete choice model. A density estimation of SATE can be obtained with $\left\{\hat{p}^{(1)}, \hat{p}^{(2)}, \ldots ., \hat{p}^{(g)}\right\}$ with the $g$-draws from $\mathbb{P}\left(\beta^{(g)} \mid \rho, \sigma_{v}^{2}\right)$ and $\mathbb{P}\left(\rho^{(g)} \mid \beta, \sigma_{v}^{2}\right)$ in the spatial probit model; then, 
GONZALES, ARANDA, MENDIZABAL Bayesian Evaluation of Micro-finance Impact

$$
C_{s c}\left(\hat{p}^{(g)}, \boldsymbol{W}\right)=\min _{j}\left\|\hat{p}_{i}^{(g)}-\delta_{j} \hat{p}_{j}^{(g)}\right\|
$$

and the full density of the SATE can be estimated with the $g=1, \ldots, G$-runs of the MCMC sampler,

$$
\left\{\mathcal{M}\left(\mathbf{t}, \mathbf{W}, \mathbf{X}, \mathbf{y}, \Theta^{(g)}\right)\right\}_{g=1}^{G}
$$

See inter alia Chib and Greenberg (2010) or Alvarez and Levin (2014). This density is useful to obtain point estimates and credible intervals: let $\vartheta$ be a SATE, a Bayesian point-estimation $\hat{\vartheta}$ is the value of $\vartheta$ that minimizes the expected value of a loss function $\ell(\hat{\vartheta}, \vartheta)$, where the expectation is taken over the posterior distribution of $\vartheta, \pi(\vartheta \mid \mathcal{D})$,

$$
\min _{\widehat{\vartheta}} \mathbb{E}[\ell(\hat{\vartheta}, \vartheta)]=\min _{\widehat{\vartheta}} \int \ell(\hat{\vartheta}, \vartheta) \pi(\vartheta \mid \mathcal{D}) d \vartheta
$$

Under quadratic loss,

$$
\min _{\widehat{\vartheta}} \mathbb{E}[\ell(\hat{\vartheta}, \vartheta)]=\min _{\widehat{\vartheta}} \int(\hat{\vartheta}-\vartheta)^{2} \pi(\vartheta \mid \mathcal{D}) d \vartheta
$$

See Geweke (2005) or Gill (2007). A $\gamma=1-\alpha$ Bayesian credible interval $\mathbb{C}_{\vartheta, \gamma}$ for the SATE can be obtained with a sub-region of the probability space parameterized by $\vartheta \in \Theta$; see inter alia Shalloway (2014). ${ }^{2}$ Compared with variance adjustment methods, the Bayesian approach guarantees positive standard errors, is more reliable in small samples compared to maximum likelihood estimation ${ }^{3}$ and can be readily employed to estimate the complete posterior distribution of the SATE. Previously, Bayesian alternatives to frequentist propensity score matching were proposed by Hoshino (2008), McCandless et al. (2009), Chib and Greenberg (2010), An (2010), Kaplan and Chen (2012), Alvarez and Levin (2014), Zigler and Dominici (2014), Zigler (2016) or Hu (2017). Hoshino (2008) analysed the effect of maternal smoking during pregnancy using a quasi-Bayesian estimation method for general parametric models that integrate out the distributions of covariates using propensity scores for latent variable models.

\footnotetext{
${ }^{2}$ As propensity score matching is a two-stage estimation technique, the standard error of the Average Treatment Effect (ATE) needs to be adjusted to account for the uncertainty in the first-stage estimation of the propensity score (Gelman and Hill, 2007).

${ }^{3}$ In the presence of small data sets, maximum likelihood estimation suffers from insufficient power and biased estimates. This issue can be solved by using Bayesian estimation in conjunction with informative prior distributions; see Van de Schoot et al. (2015).
} 
McCandless et al. (2009) evaluate the effectiveness of beta-blocker therapy in heart failure patients with a Bayesian propensity score analysis that simultaneously estimates the propensity scores and the treatment effect. Chib and Greenberg (2010), in turn, provide a Bayesian variant of the classical matching methods of Rosenbaum and Rubin (1983) for finding the causal effect of a binary intake variable. An (2010) showed that conventional propensity score estimators tend to overestimate variations in the estimates of treatment effects, whereas Bayesian propensity score matching provide correct standard errors for the estimates of treatment effects. Kaplan and Chen (2012) analyse the treatment effect of full versus part-day kindergarten attendance on reading scores for children using a two-step Bayesian propensity score approach. Alvarez and Levin (2014) use Bayesian propensity score matching to evaluate the impact of land reform on guerrilla activity in Colombia. Zigler and Dominici (2014) proposed a Bayesian method for propensity score variable selection and model averaging and they use this method to compare the effectiveness of surgical treatment for brain tumours. Finally, Zigler (2016) highlights the limitations of applying Bayesian inference to estimate propensity scores and causal effects and Hu (2017) uses Bayesian Model Averaging to deal with model-coefficient uncertainty in propensity score methods. In the case of spatial propensity score matching, Chagas et al. (2011) and De Castris and Pellegrini (2015) used this technique to incorporate spatial spillovers in impact evaluation models. Chagas et al. (2011) estimate the effect of growing sugarcane on the human development index in cane producing regions, controlling location effects with spatial econometric techniques. De Castris and Pellegrini (2015), in turn, note that the presence of a spatial interaction implies that a treatment in a region also affects also contiguous regions, violating the stable unit treatment value assumption of the Rubin model, and thus they use spatial propensity score matching to identify the regional effects of industrial subsidies. Despite these developments in Bayesian propensity score matching and spatial propensity score matching, to our knowledge, Bayesian spatial propensity score matching for impact evaluation of regional effects was never constructed before.

\section{Regional Effects of Microfinance in Bolivia}

Bolivia is an interesting case study to evaluate the regional effects of microcredit due to its paradigmatic microfinance history: the first initiatives to offer small credits in Bolivia were carried out by NGOs back in the 1980s. During the early 1990s, NGOs were transformed into regulated microfinance institutions. The rapid growth and high rates of profit of these institutions attracted more players into the market and Bolivia eventually became one of the best environments for microfinance around the world: Bolivia was listed several times as the runner-up top performer worldwide, just behind Peru, in the Global Microscope on the 
GONZALES, ARANDA, MENDIZABAL Bayesian Evaluation of Micro-finance Impact

Microfinance Business Environment sponsored by the Inter-American Development Bank — see Economist Intelligence Unit (2010) and Economist Intelligence Unit (2011). ${ }^{4}$

Using census and household survey data of Bolivia, BS-PSM was used to estimate the conditional differences between municipalities of Bolivia with and without access to microfinance. The estimated probabilities of financial access, given the spatial distance $\mathbf{W}$ and the observed covariates $\mathbf{X}$, were used to match municipalities with similar characteristics. The differences between matched municipalities were used to estimate the conditionally independent average regional impact of microfinance at municipality level in Bolivia.

Data and variables. Census information at municipality level was used to estimate the effects of microfinance in Bolivia because census data at locality/household level is not available for the public due to the data disclosure policy of the Bolivian government. Data on microcredit was gathered from the Supervisory Authority of the Financial System in Bolivia. Household survey data was used to approximate a measure of informality.

Access to microfinance was measured with the scaled number of micro-credit operations in a municipality of Bolivia. Let $\aleph_{i}$ be the number of micro-credit operations in a municipality $i=1, \ldots, n$ of Bolivia, divided by the economically active population of each municipality. The binary variable $t_{i}$ in the vector of financial access $\mathbf{t}$ is equal to,

$$
t_{i}= \begin{cases}1 & \text { if } \aleph_{i} \geq Q \\ 0 & \text { if } \aleph_{i}<Q^{\prime}\end{cases}
$$

for a threshold $Q \in \mathbb{R}^{+}$. The centiles of the number of micro-credit operations in Bolivia were used as the thresholds $Q$. This quasi-continuous estimation of the SATE allows measuring the differences in the impact on poverty, women's empowerment and informality related to the different number of microfinance operations in a municipality. This approach is similar to the dose-response function proposed by Hirano and Imbens (2004).

The $339 \times 9$ matrix of control covariates $\mathbf{X}$ is organized with 9 variables for the 339 municipalities of Bolivia:

(1) Population in the municipality.

(2) Potential labor supply, measured as the percentage of the population of working age (15 and over) with respect to total population (it shows the percentage of people who offer and could offer their labor in the labor market).

4 During 1992-2012, there was a remarkable growth of microcredit in Bolivia: in 1991 the borrowers served by agencies specializing in microfinance reached $19 \%$ of all clients in the lending market, in 2012 this percentage increase to 65\% of all clients in the lending market. Due to the advances in lending technology, microfinance is currently one of the most important financial activities in Bolivia: on September 30, 2014, the gross portfolio of specialized Microcredit Entities (MCEs) was 33\% of the total portfolio of financial intermediation in Bolivia. Of the total amount of loans allocated by MCEs, $59 \%$ were allocated to men and $41 \%$ to women. Both in terms of portfolio and number of clients, microcredit is concentrated in the major departments of Bolivia: La Paz, Santa Cruz and Cochabamba. 
(3) Poor garbage disposal: as a proxy of living conditions. This variable was measured as the percentage of the households in a municipality which do not use the public collection service (the dump truck) or dump their garbage in a public container but instead burn/bury the garbage or throw it up in the street or in a river.

(4) Place where women gave birth, different from health facilities: again a proxy of living conditions which should be (at least weakly) exogenous.

(5) Percentage of people living in rural areas.

(6) Percentage of households with access to electricity.

(7) Percentage of children in the population.

(8) Global participation rate of women, an employment indicator that is constructed to quantify the relative size of the work force.

(9) Educational units per capita, measured as the number of educational institutions in a municipality divided by the number of people living in the municipality.

Variables (1) to (8) were calculated with the public information from the 2012 National Census of Population and Households of Bolivia; (9) is based on administrative records. These variables were selected from a large set (a General Unrestricted Model, GUM) using a generalto-specific modelling approach (Campos et al., 2005) in order to satisfy the conditional independence assumption (i.e. after controlling for the covariates in $\mathbf{X}$, the potential outcomes are independent of treatment status). The GUM model—i.e. the most general statistical model that can reasonably be postulated initially, given the available sample of data, previous empirical and theoretical research, and any institutional and measurement information available (Hendry and Nielsen, 2007)—originally included several variables from the census data, such as the average years of education of the population, emigration, number of households with a vehicle or the number of own-account workers in the municipality, among other variables.

In terms of outcome variables, poverty was measured with the Unsatisfied Basic Needs (UBN) method, which is a multidimensional measure of poverty that takes into account variables as quality of housing, access to potable water, access to adequate sanitation, education, insurance, electricity and household consumption capacity; see ECLAC (2009). Female empowerment was defined as the proportion of female-headed households in a municipality which are not separated, divorced or widowed. This variable measures women's empowerment through decision-making at the household level, as women are female household heads even in the presence of a husband or partner in the household; a similar measure of empowerment was used by Yogendrarajah (2013). Lack of registration in the pension system was used as a proxy of informality, based on the records of the principal activity of the household head in the 2012 household survey of Bolivia. This legalistic definition of informality was previously used by the World Bank (2009) to analyze the reasons and the impact of informality in Bolivia.

Proximity matrix between regions. Based on the Geographic Information System (GIS) shape-file of Bolivia for the year 2012, an array of the proximity between the municipalities of 
GONZALES, ARANDA, MENDIZABAL Bayesian Evaluation of Micro-finance Impact

Bolivia was obtained (i) choosing a regional breakdown, (ii) estimating the centroids of the regional polygons, and (iii) calculating the Euclidean distance between the centroids to fulfill the Delauney triangulation condition. Figure 1 shows the result of using this procedure to calculate the proximity $339 \times 339$ matrix $\mathbf{W}$ between the municipalities of Bolivia.

Observed differences at the municipal level. Figure 2 shows the observed data of poverty and female-empowerment for the 399 municipalities of Bolivia (each dot is a municipality). In the case of informality, the household survey data does not cover all the municipalities of Bolivia but only 173 municipalities. On average in 2012, the percentage of people living in poverty according to UBN was $79.5 \%$ in municipalities without access to microfinance, and in contrast, the percentage of people living in poverty in municipalities with access to microfinance was on average 61\%, thus there was 18 percentage points (pp) less of UBN poverty in municipalities with access to microfinance in Bolivia. In terms of women's empowerment, the percentage of female-headed households in municipalities with access to microfinance was on average $25.2 \%, 2.1 \mathrm{pp}$ higher than in those municipalities without access to microfinance. Informality was equal to $14.5 \%$ in municipalities with microfinance, 5.2pp higher than in those municipalities without microfinance.

Spatial Effects of Microfinance in Bolivia. Figures 3, 4, 5 and Tables 1 and 2 show the results of using BS-PSM to estimate the effects of microfinance at regional level in Bolivia. Figures 3, 4 and 5 show the probability distribution of the differences in poverty, female empowerment and informality for each centile of microfinance treatment, next to the chains of the Markov Chain Monte Carlo (MCMC) sampler used to estimate these probability distributions. During the estimation of the BS-PSM model, a uniform prior was used for the spatial correlation coefficient $\rho, \pi(\rho) \sim U(0,1)$, assuming that the existence of financial services in a municipality should increase the chances of having financial services in neighboring municipalities, i.e. a positive spatial correlation of financial access was assumed a priori. For each outcome in each centile $Q$ of micro-credit operations, chains with 1100 iterations were simulated and a burn-in of 100 iterations was chosen to discard the nonstationary part of the chain (i.e., 110000 iterations of the MCMC sampler were ran and ten thousand iterations were discarded). Some evidence of autocorrelation was found on the simulated chains. Thinning was applied to eliminate this correlation, but the results between the thinned and the un-thinned chains were not extremely different; thus, the estimates of the SATE are based on the un-thinned chains, as nothing advantageous or necessary in thinning was found per se; see Link and Eaton (2012) for a discussion on thinning. Post-estimation tests and statistics were calculated to evaluate the spatial models, using the pseudo-R2 statistic proposed by Efron (1978) and the Bayesian version of the Smith and Todd (2005) balancing property test proposed by Gonzales (2015). 
Review of Economic Analysis 9 (2017) 127-153

Figure 1 : Delaunay Triangulation and Adjacency Matrix W
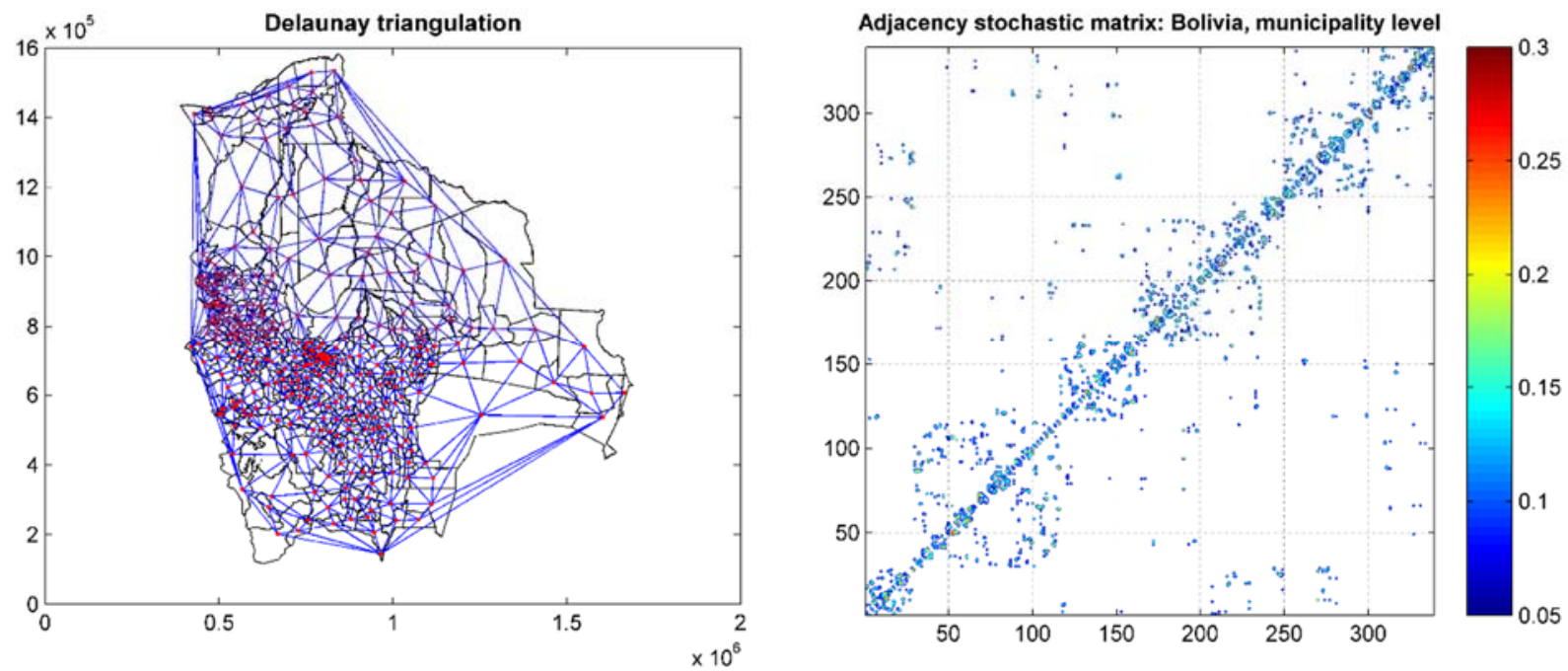

Figure 2. Observed Differences at Municipality Level
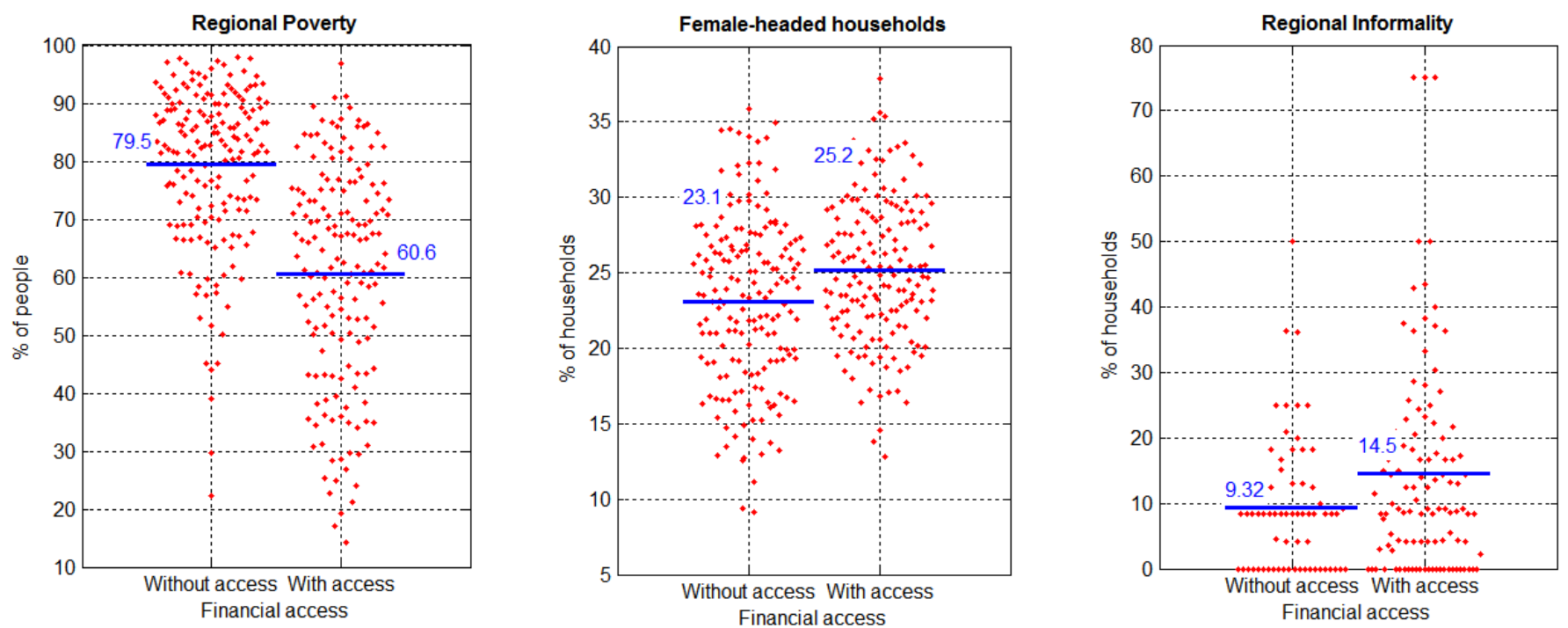

The most conclusive evidence of regional effects was obtained for poverty and women's empowerment. In the case of informality, the evidence of regional effects is weaker: 
GONZALES, ARANDA, MENDIZABAL Bayesian Evaluation of Micro-finance Impact

- Poverty. Strong evidence of microfinance effects on poverty reduction at the municipal level in Bolivia were found. The 95\% credible intervals do not include zero for any centile $Q$ of microfinance operations (Figure 3, left) and the chains of the MCMC sampler are strongly stationary for each centile (Figure 3, right). Table 1 shows that, on average, municipalities with access to microcredit tend to have around 11pp less of their population living in poverty compared with those municipalities without access to microfinance. This estimated difference in poverty is lower than the observed difference of 18pp, showing that after controlling for spatial and socio-economic characteristics the, effect of microfinance on poverty is smaller but still important with a 95\% credible interval.

- Female empowerment. In the case of women's empowerment, the estimated 95\% credible interval of the SATE was above zero for the different intensities of regional microfinance access, showing that the percentage of female-headed households was on average higher in municipalities with access to microfinance, even after controlling for the similarities between municipalities and the spatial distance between these municipalities. Again the chains of the MCMC sampler are strongly stationary in each $Q$ centile (Figure 4, right), showing a good chain convergence. Interestingly, the number of female-headed households in a municipality tends to increase as the number of regional microfinance operations increases, until reaching a peak in the 60th centile (3.27pp). See Figure 4, left.

- Informality. The evidence on informality suggests that informal activities in municipalities with microfinance is on average higher only with low and middle levels of microfinance operations (below the 60th centile) as when the intensity of microfinance operations increases above the 60th centile, the credible intervals of the SATE start crossing zero (Figure 5, left) suggesting no differences in informality when there is a large number of microfinance operations in a region. This result should be nonetheless taken with caution, as it is based on household survey data which does not cover all the municipalities of Bolivia.

In terms of post-estimation statistics (Table 2), the value of Efron's pseudo-R2 close to $50 \%$ suggests an acceptable model fit for the spatial probit models; the spatial correlation is higher for the spatial error models in the survey model of informality and the balancing tests in general point to the non-rejection of the null of balanced control covariates; nevertheless, the evidence of compliance with the balancing property is weaker for the variable estimated with survey data 
(informality), raising a concern of whether the propensity score is well estimated for this variable. The results of the Geweke convergence diagnostic (Geweke, 1992) suggest a good chain convergence in the case of poverty and women's empowerment, but not in the case of informality, casting doubt on the chain convergence for this variable and showing again that care must be taken when interpreting the results about the regional effect of microfinance on informality

Table 1. Regional Impact of Microfinance in Bolivia (pp)*

\begin{tabular}{|l|c|c|c|}
\hline & Centile 25 & Centile 50 & Centile 75 \\
\hline Poverty & $\begin{array}{c}-11.09 \\
(-12.46,-9.81)\end{array}$ & $\begin{array}{c}-12.35 \\
(-14.25,-10.82)\end{array}$ & $\begin{array}{c}-11.52 \\
(-16.31,-7.86)\end{array}$ \\
\hline Women's & 1.61 & 2.68 & 2.11 \\
empowerment & $(1.27,1.99)$ & $(2.17,3.19)$ & $(1.28,3.03)$ \\
\hline Informality & 7.55 & 6.87 & 6.04 \\
& $(6.54,8.77)$ & $(4.13,7.55)$ & $(.29,9.74)$ \\
\hline
\end{tabular}

(*) Point estimates under quadratic loss. Between brackets below each point estimate: $95 \%$ credible intervals

Figure 3. Spatial Average Treatment Effects - Poverty
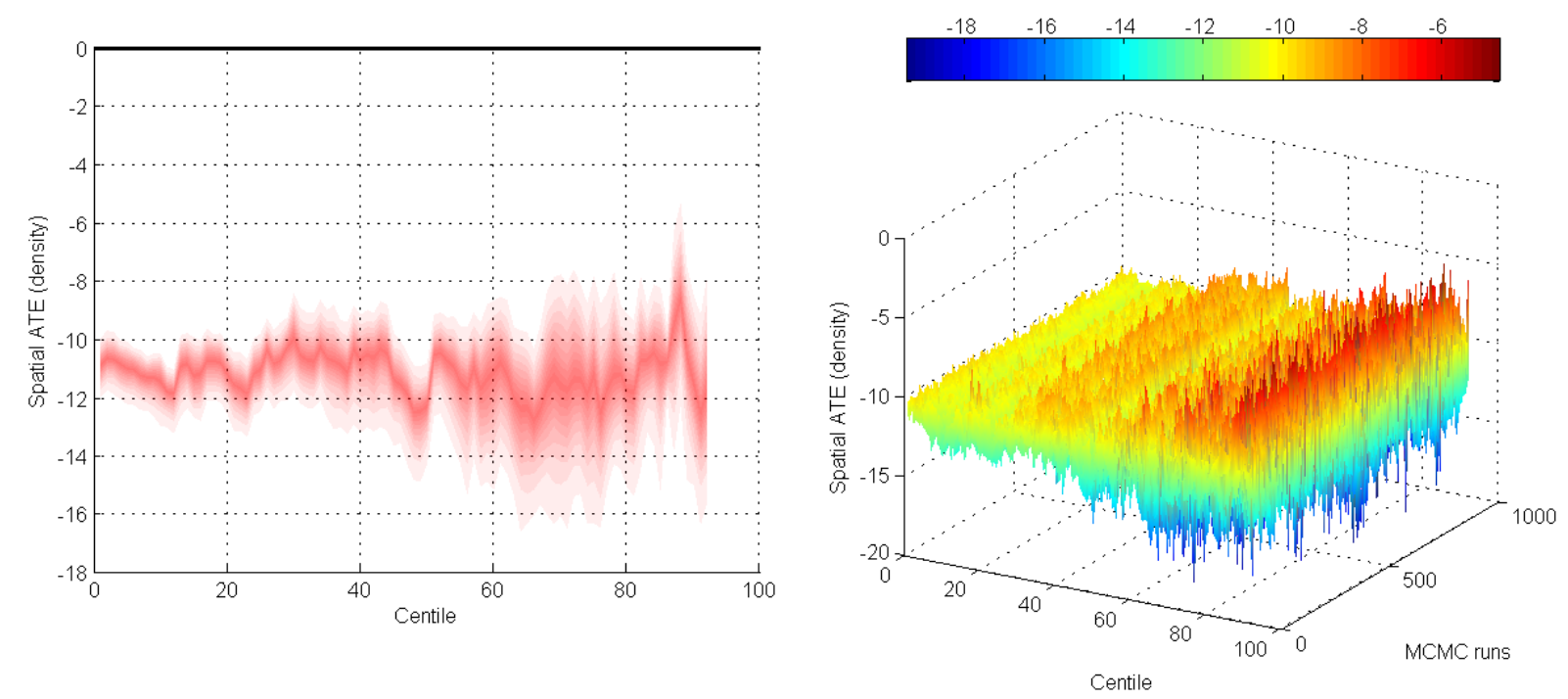
GONZALES, ARANDA, MENDIZABAL Bayesian Evaluation of Micro-finance Impact

Figure 4. Spatial Average Treatment Effects - Women's Empowerment
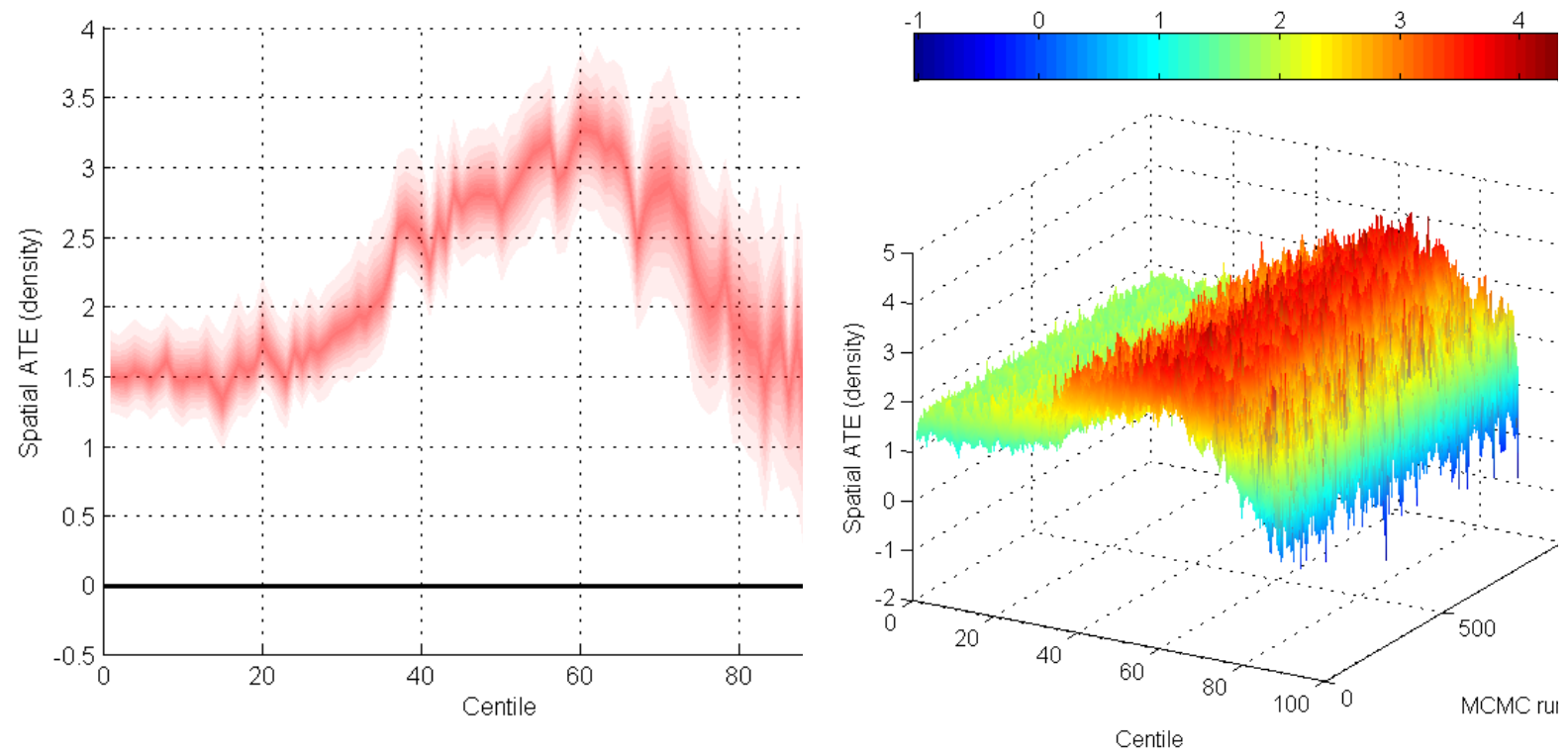

Figure 5. Spatial average treatment effects - informality
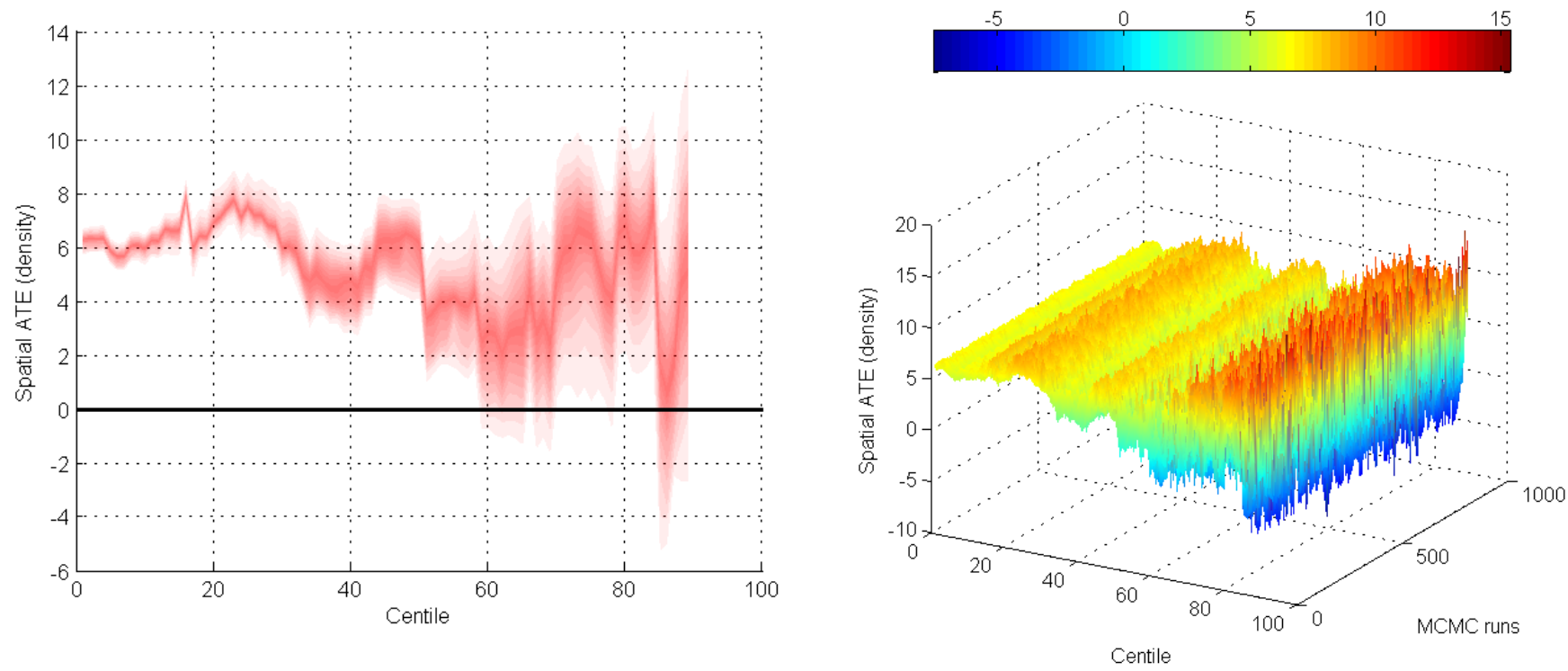
Review of Economic Analysis 9 (2017) 127-153

Table 2. Post-estimation statistics

\begin{tabular}{|c|c|c|c|}
\hline & Poverty & $\begin{array}{c}\text { Women's } \\
\text { empowerment }\end{array}$ & Informality \\
\hline \multicolumn{4}{|c|}{ Efron's pseudo-R2 } \\
\hline $\mathrm{R}^{2}$ & 52.26 & 52.02 & 45.56 \\
\hline \multicolumn{4}{|c|}{ Spatial correlation* } \\
\hline$\rho$ & $\begin{array}{c}.155 \\
(.012, .321)\end{array}$ & $\begin{array}{c}.159 \\
(.012, .391)\end{array}$ & $\begin{array}{c}.462 \\
(.053, .88)\end{array}$ \\
\hline \multicolumn{4}{|c|}{ Spatial probit estimates $^{\dagger}$} \\
\hline $\mathbf{x}_{0}$ & -33.954 & -34.429 & -31.815 \\
\hline $\mathbf{x}_{1}$ & .6644 & .6475 & .3816 \\
\hline $\mathbf{x}_{2}$ & .3277 & .3307 & .3090 \\
\hline $\mathbf{x}_{3}$ & -.020 & -.019 & -.031 \\
\hline $\mathbf{x}_{4}$ & -.027 & -.027 & -.024 \\
\hline $\mathbf{x}_{5}$ & .0002 & .0001 & .0044 \\
\hline $\mathbf{x}_{6}$ & .2213 & .2479 & -1.0353 \\
\hline $\mathbf{x}_{7}$ & .0095 & .0099 & .0024 \\
\hline $\mathbf{x}_{8}$ & .2303 & .2342 & .2501 \\
\hline $\mathbf{x}_{9}$ & .0279 & .0288 & .0367 \\
\hline \multicolumn{4}{|c|}{ Balancing tests ${ }^{\ddagger}$} \\
\hline $\mathbf{x}_{1}$ & .4691 & .4719 & .2424 \\
\hline $\mathbf{x}_{2}$ & .1167 & .1148 & .0300 \\
\hline $\mathbf{x}_{3}$ & .3434 & .3607 & .2001 \\
\hline $\mathbf{x}_{4}$ & .0876 & .1010 & .0531 \\
\hline $\mathbf{x}_{5}$ & .3685 & .3861 & .1183 \\
\hline $\mathbf{x}_{6}$ & .0438 & .0473 & .0189 \\
\hline $\mathbf{x}_{7}$ & .0487 & .0550 & .2074 \\
\hline $\mathbf{x}_{8}$ & .1066 & .1027 & .0278 \\
\hline $\mathbf{x}_{9}$ & .0671 & .0759 & .0261 \\
\hline \multicolumn{4}{|c|}{ Geweke Convergence Diagnostic } \\
\hline & .4263 & .9512 & .0111 \\
\hline
\end{tabular}

(*) Between brackets below each point estimate: $95 \%$ credible intervals $(\dagger)$ Bayesian point estimates. The term $\mathbf{x}_{0}$ is the constant in the spatial models

( $\ddagger$ ) Bayesian p-values for the null of balanced variable

(`) p-values for the null of equal mean in the fractions of the chain. The test was run using the $50^{\text {th }}$ centile of the SATE chains and fractions of $10 \%$ and $50 \%$ at the start and the end of the chain, respectively. 
GONZALES, ARANDA, MENDIZABAL Bayesian Evaluation of Micro-finance Impact

To further evaluate the possibility of spurious associations, Appendix I at the end of the study runs a falsification test for the BS-PSM algorithm, based on the pre-specified false hypotheses that microfinance is causally related to the percentage of people with deafness in a municipality. The results showed a lack of confirmation of the improbable link of microfinance with deafness, supporting the conclusions about the associations of interest in the study. Appendix II also shows the consequences of both using a traditional matching technique (nearest neighbors) and removing the spatial effect, in order to compare the BS-PSM algorithm with the current modeling approaches. The results show that the estimates of SATE with and without spatial effects are almost the same, very likely due to the low value of the estimated spatial correlation coefficient $\hat{\rho}$ (Table 2). In contrast, the estimation based on a traditional non-spatial nearest neighbor matching produce a multimodal estimation of the regional ATE. This last result suggests that the estimation of the SATE can be sensitive to the inclusion/exclusion of spatial effects during the matching, but not to the estimation of the propensity score probabilities when there is low spatial correlation.

\section{Conclusions}

Bayesian Spatial-Propensity Score Matching was proposed to evaluate the regional effects of microfinance on poverty, informality and women's empowerment in Bolivia. Compared to other studies that found that microfinance contributes to poverty reduction at individual or household level—e.g. Wright (2000), Morduch and Haley (2002) or Khandker (2005)—, a positive impact on poverty reduction at municipality level was also found with BS-PSM in Bolivia. The Bayesian SATE also showed strong evidence of female empowerment through decision-making at the household level in municipalities with microfinance access in Bolivia. The favorable effect of microfinance on female empowerment is similar to that obtained by inter alia Rahman (1986), Pitt and Khandker (1998), Pitt et al. (2006) or Swain and Wallentin (2009) - see also the discussion of Roodman and Morduch (2009) about the results of Pitt and Khandker (1998). ${ }^{5}$ The results for Bolivia also suggest that the possible cost of poverty reduction and female empowerment could have been an increase in informality. As currently the access to micro-credit in Bolivia identifies income generation (payment capacity) as the main requirement that must be evaluated when granting a loan, regardless of whether the economic activity of the applicant has all legal documents for formal operation, microfinance could be adding up to the structural factors that cause informality in Bolivia-regulatory burden, weak institutions and lack of perceived benefits for being formal (World Bank, 2009).

\footnotetext{
${ }^{5}$ The findings are conditional on the fulfilment of the un-confoundedness assumption and on the assumptions behind ecological regression; see e.g. Gelman et al. (2001) for a discussion. Future studies can explore the possibility of expanding the BS-PSM algorithm with multilevel data through the inclusion of individual-level data at the regional level and the use of procedures described in inter alia Li et al. (2013).
} 
Nevertheless, as the evaluation of the regional impact of microfinance on informality with the BS-PSM model is based on household survey data, which does not cover all the regions of Bolivia, and suffers from estimation problems related to unbalanced covariates and nonconvergent chains, the results on informality cannot be considered conclusive. ${ }^{6}$

From a methodological point of view, BS-PSM seems to be an interesting option over traditional matching estimators: the BS-PSM model allows to take into account spatial factors during the matching, which are important if the distance to financial institutions is a constraint to financial inclusion and affects regional growth; also, the full density of the spatial regional effects can be estimated with the Bayesian approach, thus making possible to perform a rigorous inferential analysis based on probabilistic credible intervals without the need of variance adjustment corrections. ${ }^{3}$ Despite these clear advantages, it is worth noting that BS-PSM identifies regional effects without explicitly identifying the source of these effects. Future work can concentrate on improving this limitation in an effort to identify the mechanisms behind the impact of microfinance at regional level, because (i) if the transmission channels are related to intra-household allocation, a proper policy will be to give more power to women to control their resources, (ii) but if the channels are ancillary industries, there is a need to strength the human resources and institutions that provide financial services in remote areas; and finally, (iii) if the transmission channels are caused by impacts on consumption that have local multiplier effects, then no additional policy may be needed, as the multiplier mechanisms are already working.

\section{Appendix I. Falsification Test for the BS-PSM Algorithm}

A falsification test was run to evaluate possible false positives of the BS-PSM algorithm. The pre-specified falsification hypotheses is that microfinance is causally related to the percentage of people with deafness in a municipality, a hypotheses which is highly unlikely to be true. Figure A.1 shows the observed differences in deafness of municipalities with and without access to microfinance; the descriptive results point to a higher percentage of people

\footnotetext{
${ }^{6}$ In terms of policy relevance for Bolivia, the results of the regional impact evaluation are useful to inform evidence-based policy decisions for the New Development Plan and the New Law of Financial Services of this country. The New Development Plan of Bolivia aims to develop a financial system for integral development committed to poverty eradication through loan provision, financial services and financial access. In the case of the New Law of Financial Services, it goes beyond prudential regulation and seeks to improve financial access and income for low-income populations, as states that financial access must be on a basis of equal treatment, without discrimination because of age, gender, race, religion or cultural identity. In this context, the findings of positive regional effects of microfinance for women's empowerment and poverty suggest that the government has to encourage the environment for microfinance and further expand financial access and loan provision at regional level, since the possible cost of increasing informality may not be relevant compared with the primary objective of reducing poverty.
} 
GONZALES, ARANDA, MENDIZABAL Bayesian Evaluation of Micro-finance Impact

with deafness in municipalities without access to microfinance $(.75 \%)$ compared to municipalities with access to microfinance (.65\%). Figure A.2 shows the results of the Bayesian estimation of the SATE of microfinance on deafness, based on the BS-PSM algorithm. The 95\% credible intervals cross zero frequently, providing no evidence in favour of the prespecified false hypotheses. The lack of confirmation of an improbable link of microfinance with deafness, supports the conclusions about the associations of interest in the study.

Figure A.1. Observed Differences in Deafness of Municipalities with and without Access to Microfinance.

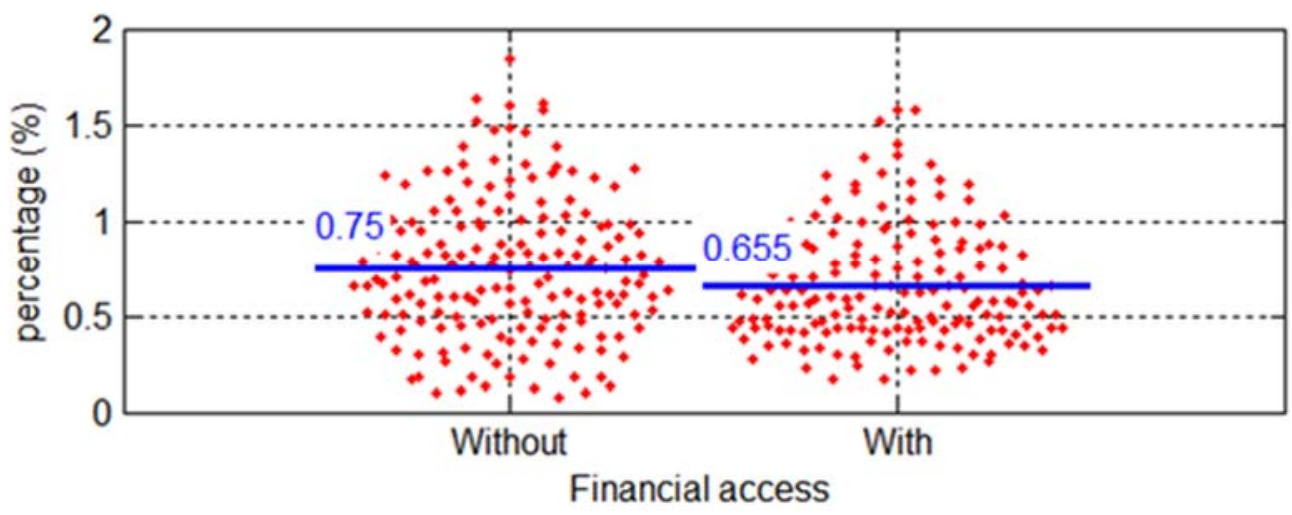

Figure A.2. Average Difference in Deafness (of Municipalities with and without Access to Microfinance) Estimated with BS-PSM

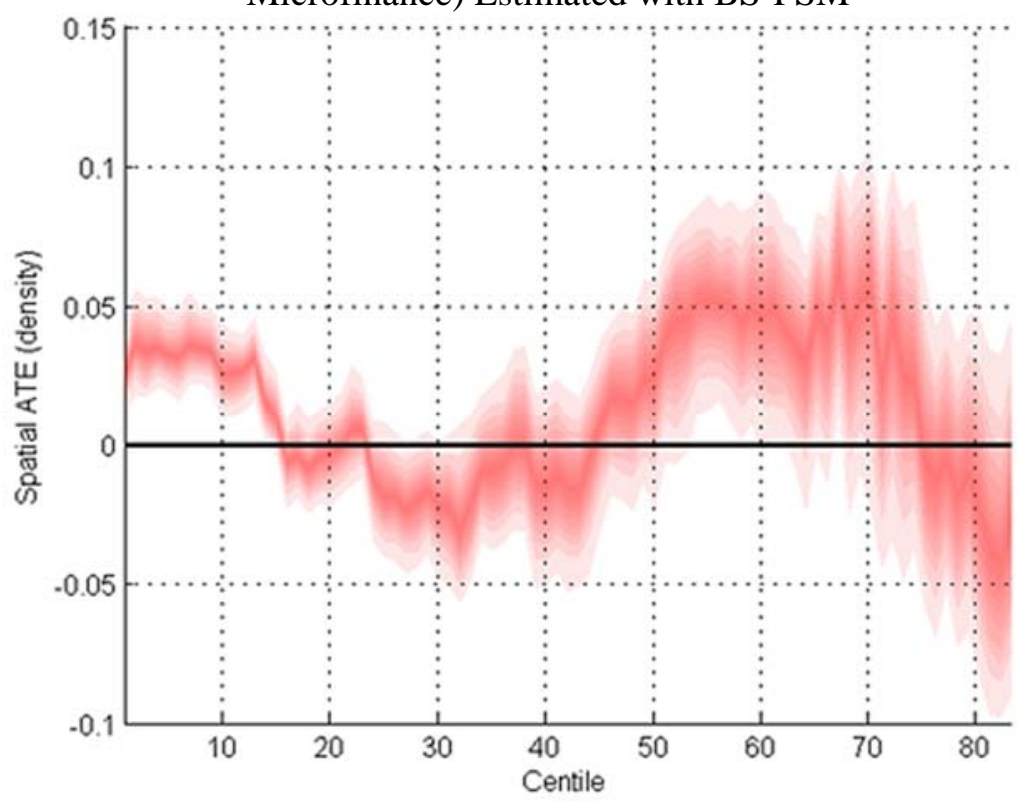


Appendix II. Sensitivity of the results to the matching technique and the exclusion of spatial effects

Sensitivity of the results to the exclusion of spatial information was evaluated by changing the prior of the spatial correlation coefficient of the probit function to $\rho \sim \mathcal{U}(-1,0.1$ ) (which includes no spatial correlation) instead of $\rho \sim \mathcal{U}(0,1)$ (positive spatial correlation a priori) and using a conventional nearest neighbor matching instead of the spatial caliper matching proposed in the study. The posterior estimation of $\rho$ includes zero with a 95\% probability (see Figures A.4b, A.6b and A.8b), i.e. no spatial correlation was assumed $a$ priori in the probit model that was used to estimate the propensity scores. The estimates of SATE based on the assumption of no spatial correlation do not seem to be affected by this assumption, as the results with and without spatial information are almost the same, as can be seeing by a comparison of Figures A.3d with A.4d, A.5d with A.6.d and A.7d with A.8.d. In contrast to the previous results, the estimation based on a traditional non-spatial nearest neighbor matching produce a multimodal estimation of the regional ATE. This last result suggests that the estimation of the SATE is sensitive to the inclusion/exclusion of spatial effects during the matching, but not during the estimation of the matching probabilities. See and compare Figures A.3d with A.3f, A.4d with A.4f, A.5d with A.5f, A.6d with A.6f, A.7d with A.7f and A.8d with A.8f.

(a)

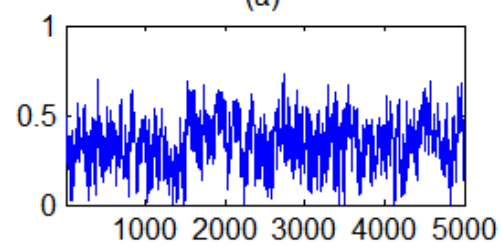

(c)

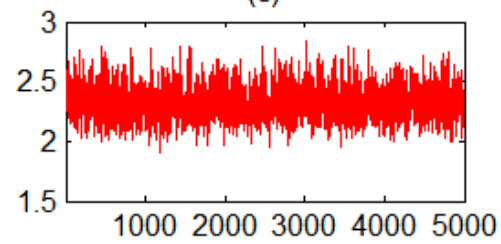

(e)

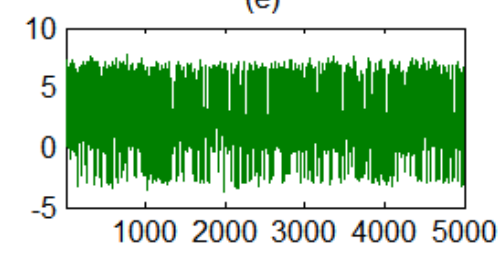

(b)

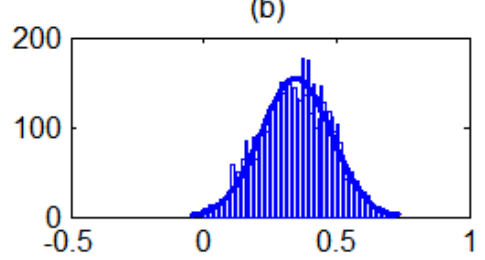

(d)

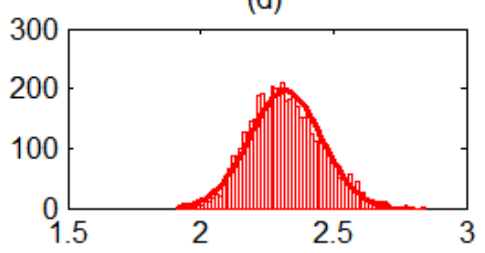

(f)

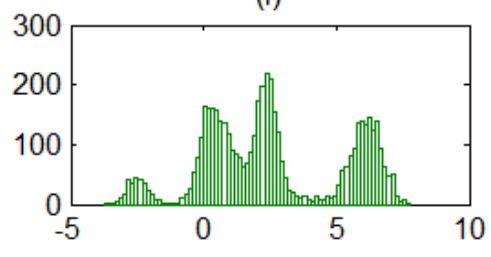

Figure A.3. Estimation of SATE for women's empowerment with spatial information.

(a) MCMC runs of $\hat{\rho}$ with a prior $\rho \sim \mathcal{U}(0,1)$.

(b) Histogram of $\hat{\rho}$.

(c) MCMC runs of SATE with spatial caliper

matching.

(d) Histogram of SATE with spatial caliper matching. (e) MCMC runs of SATE without spatial matching. (f) Histogram of SATE without spatial matching. 
GONZALES, ARANDA, MENDIZABAL Bayesian Evaluation of Micro-finance Impact

(a)

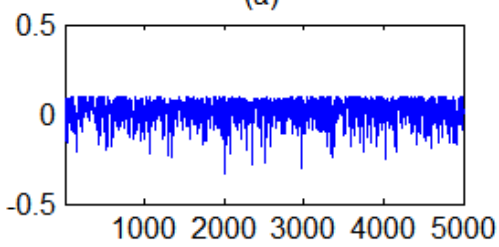

(c)

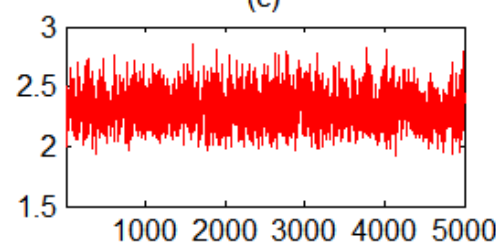

(e)

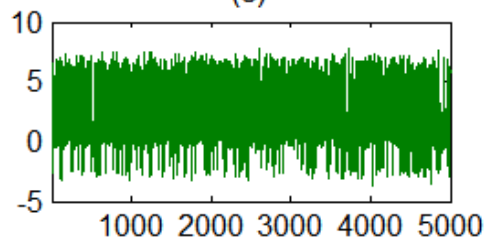

(a)

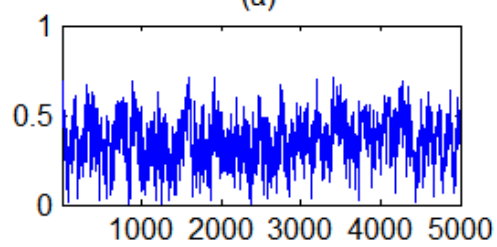

(c)

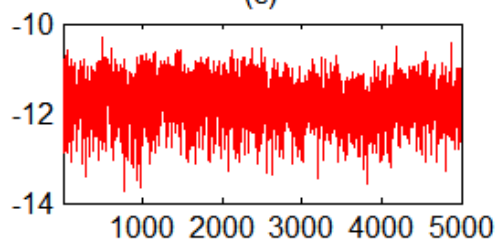

(e)

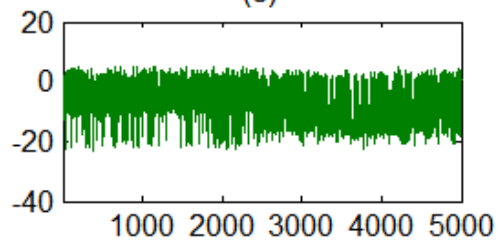

(b)

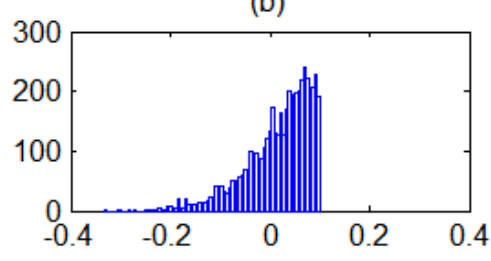

(d)

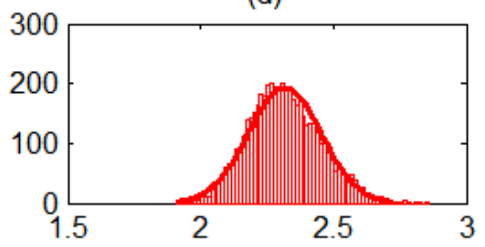

(f)

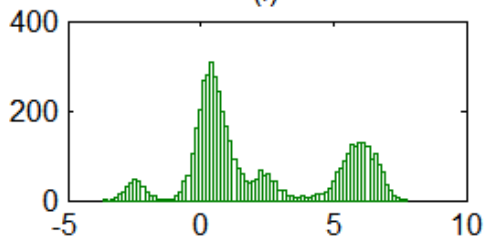

(b)

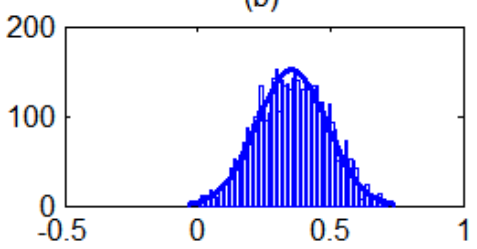

(d)

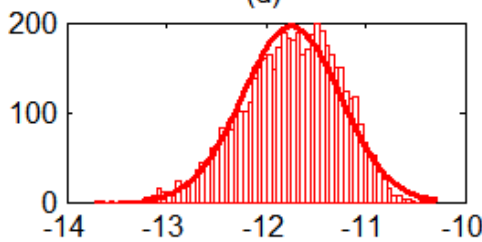

(f)

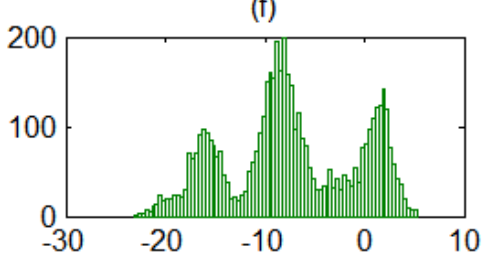

Figure A.4. Estimation of SATE for women's empowerment without spatial information.

(a) MCMC runs of $\hat{\rho}$ with a prior $\rho \sim \mathcal{U}(-1,0.1)$.

(b) Histogram of $\hat{\rho}$.

(c) MCMC runs of SATE with spatial caliper matching.

(d) Histogram of SATE with spatial caliper matching.

(e) MCMC runs of SATE without spatial matching. (f) Histogram of SATE without spatial matching.

Figure A.5. Estimation of SATE for poverty with spatial information.

(a) MCMC runs of $\hat{\rho}$ with a prior $\rho \sim \mathcal{U}(0,1)$.

(b) Histogram of $\hat{\rho}$.

(c) MCMC runs of SATE with spatial caliper matching.

(d) Histogram of SATE with spatial caliper matching. (e) MCMC runs of SATE without spatial matching. (f) Histogram of SATE without spatial matching. 
(a)

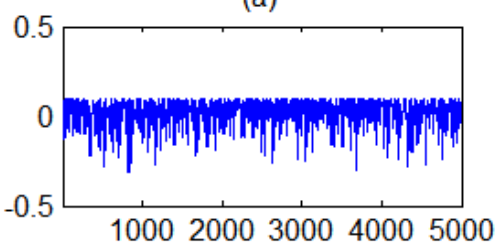

(c)

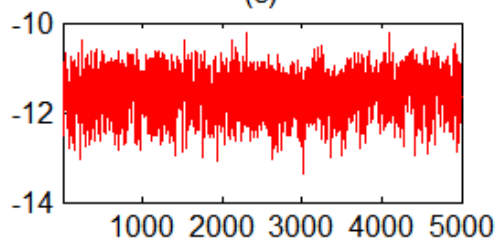

(e)

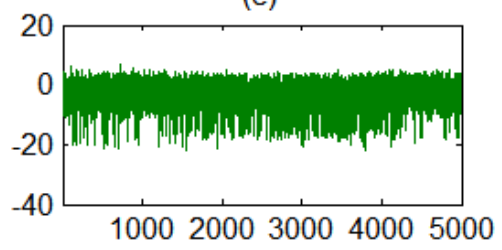

(a)

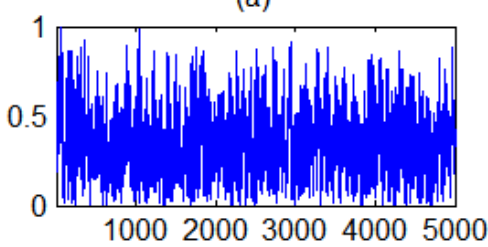

(c)

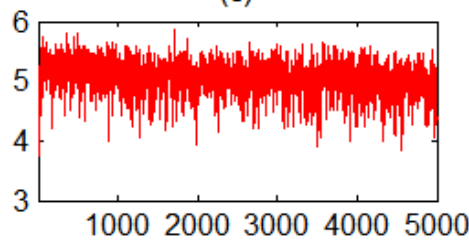

(e)

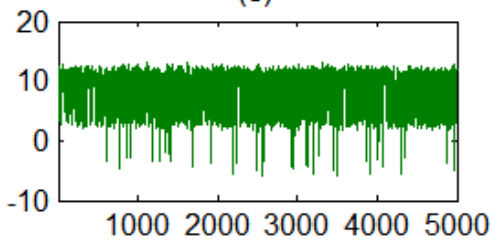

(b)

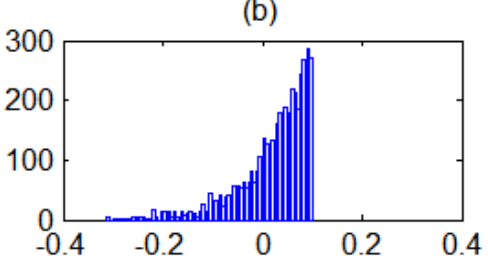

(d)

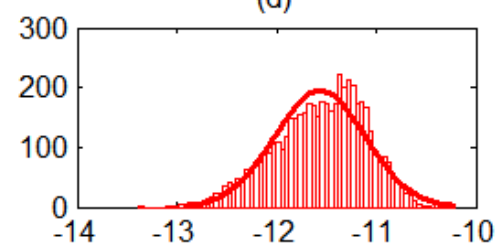

(f)

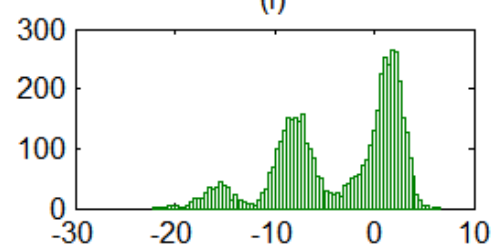

(b)

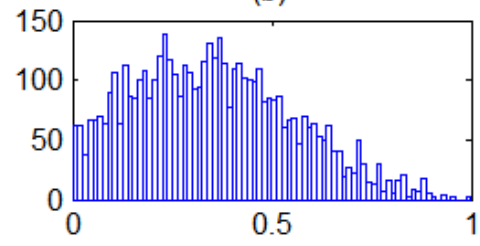

(d)

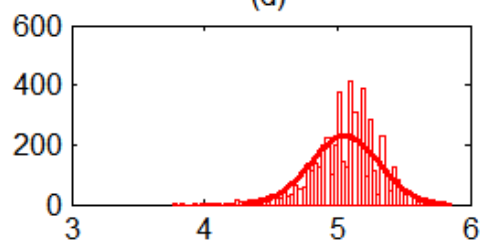

(f)

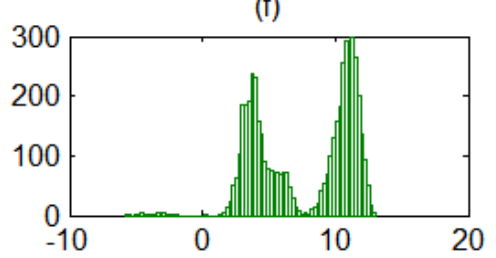

Figure A.6. Estimation of SATE for poverty without spatial information.

(a) MCMC runs of $\hat{\rho}$ with a prior $\rho \sim \mathcal{U}(-1,0.1)$.

(b) Histogram of $\hat{\rho}$.

(c) MCMC runs of SATE with spatial caliper matching.

(d) Histogram of SATE with spatial caliper matching. (e) MCMC runs of SATE without spatial matching. (f) Histogram of SATE without spatial matching.

Figure A.7. Estimation of SATE for poverty with spatial information.

(a) MCMC runs of $\hat{\rho}$ with a prior $\rho \sim \mathcal{U}(0,1)$.

(b) Histogram of $\hat{\rho}$.

(c) MCMC runs of SATE with spatial caliper matching.

(d) Histogram of SATE with spatial caliper matching.

(e) MCMC runs of SATE without spatial matching. (f) Histogram of SATE without spatial matching. 
GONZALES, ARANDA, MENDIZABAL Bayesian Evaluation of Micro-finance Impact

(a)

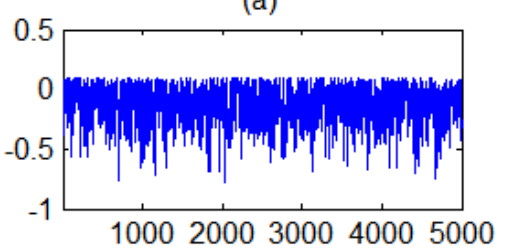

(c)

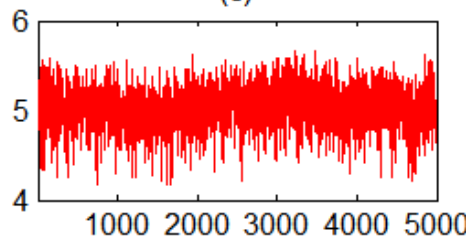

(e)

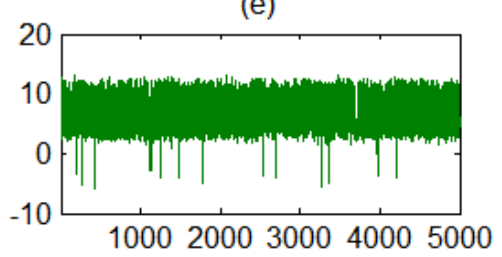

(b)

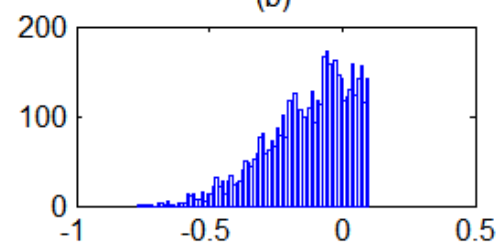

(d)

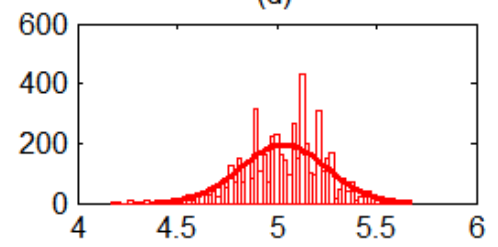

(f)

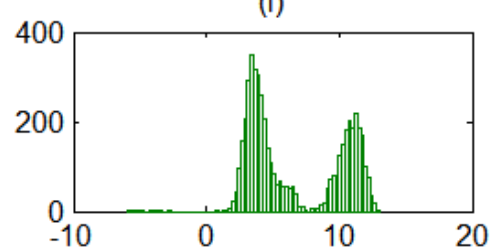

Figure A.8. Estimation of SATE for poverty without spatial information.

(a) MCMC runs of $\hat{\rho}$ with a prior $\rho \sim \mathcal{U}(-1,0.1)$.

(b) Histogram of $\hat{\rho}$.

(c) MCMC runs of SATE with spatial caliper matching.

(d) Histogram of SATE with spatial caliper matching.

(e) MCMC runs of SATE without spatial matching. (f) Histogram of SATE without spatial matching.

\section{References}

Abadie, A. and G.W. Imbens (2008). On the failure of the bootstrap for matching estimators. Econometrica, 76(6), 1537-1557.

Abadie, A. and G.W. Imbens (2009). Matching on the estimated propensity score. NBER Working Papers 15301, National Bureau of Economic Research.

Albert, J.H. and S. Chib (1993). Bayesian analysis of binary and polychotomous response data. Journal of the American Statistical Association, 88(422), 669-679.

Alvarez, M. and I. Levin (2014). Uncertain neighbors: Bayesian propensity score matching for causal inference. Technical report, California Institute of Technology, University of Georgia.

An, W. (2010). Bayesian propensity score estimators: Incorporating uncertainties in propensity scores into causal inference. Sociological Methodology, 40(1), 151-189.

Anselin, L. (1988). Spatial econometrics: Methods and models. Volume 4. Springer.

Anselin, L. And R. Florax (2011). New directions in spatial econometrics. Advances in spatial science. Springer Berlin Heidelberg.

Arbia, G. (2010). Spatial econometrics: Statistical foundations and applications to regional convergence. Advances in spatial science. Springer Berlin Heidelberg.

Banerjee, A., D. Karlan, and J. Zinman (2015). Six randomized evaluations of microcredit: Introduction and further steps. American Economic Journal: Applied Economics, 7(1), $1-21$.

Bateman, M. (2010). Why doesn't microfinance work? The destructive rise of local neoliberalism. Zed Books London-New York. 
Bateman, M. (2013). The age of microfinance: Destroying Latin American economies from the bottom up. Working Papers 39. Austrian Foundation for Development Research.

Bateman, M. and H.-J. Chang (2009). The microfinance illusion. Unpublished manuscript. Cambridge: University of Cambridge.

Bauwens L., M. Lubrano and J.F. Richard (2000). Bayesian inference in dynamic econometric models. Oxford University Press.

Brett, J.A. (2006). We sacrifice and eat less: The structural complexities of microfinance participation. Human Organization, 65(1), 8-19.

Caliendo, M. and S. Kopeinig (2008). Some practical guidance for the implementation of propensity score matching. Journal of Economic Surveys, 22(1), 31-72.

Campos, J., N.R. Ericsson, and D.F. Hendry (2005). General-to-specific modeling: an overview and selected bibliography. International Finance Discussion Papers 838, Board of Governors of the Federal Reserve System (U.S.).

Capello, R. (2009). Spatial spillovers and regional growth: A cognitive approach. European Planning Studies, 17(5), 639-658.

Chagas, A.L.S., R. Toneto and C.R. Azzoni (2011). A spatial propensity score matching evaluation of the social impacts of sugarcane growing on municipalities in Brazil. International Regional Science Review.

Chib, S. and E. Greenberg (2010). Bayesian matching for causal inference. Technical report, Washington University in St. Louis, Yale University.

Chowdhury, A.M.R. and A. Bhuiya (2004). The wider impacts of BRAC poverty alleviation programme in Bangladesh. Journal of International Development, 16(3), 369-386.

Chowdhury, A., R. Mushtaque, P. Mosley and A. Simanowitz (2004). The social impact of microfinance. Introduction. Journal of International Development, 16, 291-300.

Corrado, L. and B. Fingleton (2012). Where is the economics in spatial econometrics? Journal of Regional Science, 52(2), 210-239.

De Castris, M. and G. Pellegrini (2015). Neighborhood Effects On The Propensity Score Matching. Working Paper 05/5, CREI Università degli Studi Roma Tre.

ECLAC (2009). Income poverty and unsatisfied basic needs. Project and research documents lc/mex/l.949, Economic Commission for Latin America and the Caribbean (ECLAC).

Economist Intelligence Unit (2010). Global microscope on the microfinance business environment 2010. Inter-American Development Bank.

Economist Intelligence Unit (2011). Global microscope on the microfinance business environment 2011. Inter-American Development Bank.

Elhorst, J. (2014). Linear spatial dependence models for cross section data. In Spatial Econometrics, Springer Briefs in Regional Science, pp. 5-36. Springer Berlin Heidelberg.

Efron, B. (1978). Regression and ANOVA with zero-one data: Measures of residual variation. Journal of the American Statistical Association, 73(361), 113-121.

Efron, B. (2013). Bayes' theorem in the 21st century. Science 340.

Gelman, A. and J. Hill (2007). Data analysis using regression and multilevel/hierarchical models. New York: Cambridge University Press. 
GONZALES, ARANDA, MENDIZABAL Bayesian Evaluation of Micro-finance Impact

Gelman, A., D.K. Park, S. Ansolabehere, P.N. Price and L.C. Minnite (2001). Models, assumptions and model checking in ecological regressions. Journal of the Royal Statistical Society: Series A (Statistics in Society), 164(1), 101-118.

Geweke, J. (2005). Contemporary Bayesian econometrics and statistics. Wiley Series in Probability and Statistics. Wiley.

Geweke, J. (1992). Evaluating the accuracy of sampling-based approaches to the calculation of posterior moments. In Bayesian Statistics 4, eds. J. M. Bernardo, J. Berger, A. P. David, and A. F. M. Smith, Oxford, U.K.: Oxford University Press, pp. 169-193.

Gill, J. (2007). Bayesian methods: A social and behavioral sciences approach, 2nd ed. Chapman \& Hall/CRC Statistics in the Social and Behavioral Sciences. Taylor \& Francis.

Glennerster, R. and K. Takavarasha (2013). Running randomized evaluations: A practical guide. Princeton University Press.

Gonzales, R. (2010). On the importance of credit for regional economic development in Bolivia: an analysis with non-parametric inference, spatial econometrics and Bayesian methods. Central Bank of Bolivia Research Award.

Gonzales, R. (2015). A natural-conjugate Bayesian version of the Smith-Todd balancing test. Technical Report 01/2015, Bayesian Institute for Research on Development.

Griffith, D.A., J.H.P. Paelinck (2011). Non-standard spatial statistics and spatial econometrics. Springer Science \& Business Media.

Hendry, D. and B. Nielsen (2007). Econometric modeling: a likelihood approach. Princeton University Press.

Hirano, K. and G.W. Imbens (2004). The propensity score with continuous treatments. Applied Bayesian modeling and causal inference from incomplete-data perspectives, 2004, vol. 226164, p. 73-84.

Hoshino, T. (2008). A Bayesian propensity score adjustment for latent variable modeling and MCMC algorithm. Computational Statistics and Data Analysis, 52(3), 1413-1429.

Hu, A. (2017). Uncertainty of Statistical Models and Propensity Score Methods. Chinese Journal of Sociology. Vol. 37, $\mathrm{N}^{\circ} 1$.

Johnson, S. (2004). The impact of microfinance institutions in local financial markets: a case study from Kenya. Journal of International Development, 16(3), 501-517.

Khalily, M.A.B. (2004). Quantitative approach to impact analysis of microfinance programs in Bangladesh: what have we learned? Journal of International Development, 16(3), 331-353.

Khandker, S.R. (2005). Microfinance and poverty: Evidence using panel data from Bangladesh. The World Bank Economic Review, 19(2), 263-286.

Kaplan, D. and J. Chen (2012). A two-step Bayesian approach for propensity score analysis: Simulations and case study. Psychometrika, 77(3), 581-609.

Karlan, D.S. and N. Goldberg (2007). Impact evaluation for microfinance: Review of methodological issues. World Bank, Poverty Reduction and Economic Management, Thematic Group on Poverty Analysis, Monitoring and Impact Evaluation.

Lesage, J. P. (2000). Bayesian estimation of limited dependent variable spatial autoregressive models. Geographical Analysis, 32(1), 19-35. 
Lesage, J. and R. Pace (2009). Introduction to spatial econometrics. Boca Raton (USA): Chapman-Hall.

Li, F., A.M. Zaslavsky and M.B. Landrum (2013). Propensity score weighting with multilevel data. Statistics in Medicine, 32(19), 3373-3387.

Link, W.A. and M.J. Eaton (2012). On thinning of chains in MCMC. Methods in Ecology and Evolution, 3(1), 112-115.

McCandless, L., P. Gustafson, P. Austin and A. Levy (2009). Covariate balance in a Bayesian propensity score analysis of beta blocker therapy in heart failure patients. Epidemiologic Perspectives and Innovations, 6(1), 5.

MkNelLY, B. and C. Dunford (1999). Impact of credit with education on mothers and their young children's nutrition: Crecer credit with education program in Bolivia. Freedom from Hunger Research Paper 5.

Mcintosh, C. (2008). Estimating treatment effects from spatial policy experiments: An application to Ugandan microfinance. The Review of Economics and Statistics, 90(1), $15-28$.

Morduch, J. and B. Haley (2002). Analysis of the effects of microfinance on poverty reduction. Technical report, NYU Wagner Working Paper

Mosley, P. (2001). Microfinance and poverty in Bolivia. Journal of Development Studies, 37(4), 101-132.

Mosley, P. (2003). Micro-insurance: scope, design and assessment of wider impacts. IDS bulletin, vol. 34, no 4, p. 143-155.

Mosley, P. and J. Rock (2004). Microfinance, labour markets and poverty in Africa: a study of six institutions. Journal of International Development, 16(3), 467-500.

Navajas, S., M. Schreiner, R.L. Meyer, C. Gonzalez-Vega and J. Rodriguez-Meza (2000). Microcredit and the poorest of the poor: Theory and evidence from Bolivia. World Development, 28(2), 333-346.

Pitt, M.M. and S.R. Khandker (1998). The impact of group-based credit programs on poor households in bangladesh: Does the gender of participants matter? Journal of Political Economy, 106(5), 958-996.

Pitt, M.M., S.R. Khandker and J. Cartwright (2006). Empowering women with micro finance: Evidence from Bangladesh. Economic Development and Cultural Change, 54(4), 791-831

Rahman, R.I. (1986). Impact of Grameen bank on the situation of poor rural women. Grameen Bank Evaluation Project Working Paper 1.

Roodman, D. and J. Morduch (2009). The impact of microcredit on the poor in Bangladesh: Revisiting the evidence. Center for Global Development Working Paper (174).

Rosenbaum, P.R. and D.B. Rubin (1983). The central role of the propensity score in observational studies for causal effects. Biometrika, 70(1), 41-55.

Shalloway, D. (2014). The evidentiary credible region. Bayesian Analysis, 9(4), 909-922.

Smith, T.E. and J.P. Lesage (2004). A Bayesian probit model with spatial dependencies. Advances in Econometrics, 18, 127-160.

Smith, J. and P. Todd (2005). Rejoinder. Journal of Econometrics, 125(1-2), 365-375.

Swain, R.B. and F.Y. Wallentin (2009). Does microfinance empower women? Evidence from self-help groups in India. International Review of Applied Economics, 23(5), 541556. 
GONZALES, ARANDA, MENDIZABAL Bayesian Evaluation of Micro-finance Impact

Van de Schoot, R., Broere, J. J., Perryck, K. H., Zondervan-Zwijnenburg, M., and Van loey, N. E. (2015). Analysing small data sets using Bayesian estimation: the case of posttraumatic stress symptoms following mechanical ventilation in burn survivors. European Journal of Psychotraumatology, Vol. 6.

Velasco, C. and R. Marconi (2004). Group dynamics, gender and microfinance in Bolivia. Journal of International Development, 16(3), 519-528.

Warren, S. F., M. E. Fey and P. J. Yoder (2007). Differential treatment intensity research: A missing link to creating optimally effective communication interventions. Mental Retardation and Developmental Disabilities Research Reviews, 13(1), 70-77

Weiss, J. and H. Montgomery (2005). Great expectations: microfinance and poverty reduction in Asia and Latin America. Oxford Development Studies, 33(3-4), 391-416.

World Bank (2009). Increasing formality and productivity of Bolivian firms. Country Studies. World Bank.

Wright, G.A. (2000). Microfinance systems: Designing quality financial services for the poor. Zed books London.

Wright, K. and J. Copestake (2004). Impact assessment of microfinance using qualitative data: communicating between social scientists and practitioners using the quip. Journal of International Development, 16(3), 355-367.

Yogendrarajah, R. (2013, December). Women Empowerment through Decision Making. The International Journal of Economics and Business Management, 3(1).

Zigler, C. M. (2016). The Central Role of Bayes’ Theorem for Joint Estimation of Causal Effects and Propensity Scores. The American Statistician, 70(1), 47-54.

Zigler, C.M. and F. Dominici (2014). Uncertainty in propensity score estimation: Bayesian methods for variable selection and model-averaged causal effects. Journal of the American Statistical Association, 109(505), 95-107.

Zohir, S. and I. Matin (2004). Wider impacts of microfinance institutions: issues and concepts. Journal of International Development, vol. 16, no 3, p. 301-33. 